\title{
Protective Effects of Tetramethylpyrazine on Glutamate-Induced Neurotoxicity in Mice
}

\author{
Yongping Zhang ${ }^{1}$, Zimo Huang ${ }^{2}$, Lijiang Yu ${ }^{1^{*}}$, Libin Zhang ${ }^{3}$ \\ ${ }^{1}$ College of Food Science and Technology, Guangdong Ocean University, Zhanjiang, China \\ ${ }^{2}$ Medical College of Shantou University, Shantou, China \\ ${ }^{3}$ The Affiliated Hospital of Guangdong Medical College, Zhanjiang, China

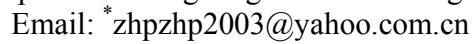

Received April 9, 2012; revised May 6, 2012; accepted May 17, 2012

\begin{abstract}
The aim of this study was to investigate the potential protective effect of tetramethylpyrazine (TMP), one of available blood-activating and stasis-eliminating components from traditional Chinese medicines, on glutamate-induced neurotoxicity in mice and its possible mechanism. Mice, except for controls, received simultaneously intragastric (ig) administration of monosodium glutamate [MSG, $4.0 \mathrm{~g} /(\mathrm{kg} \cdot \mathrm{d})]$ or/and intraperitoneal (ip) administration of TMP [10, 20, 40 $\mathrm{mg} /(\mathrm{kg} \cdot \mathrm{d})]$ for $10 \mathrm{~d}$, and then behavioral tests, as well as histopathological and immunohistochemical examination of hippocampi were performed to analyze the glutamate-induced functional and morphological changes and the possible protective effect of TMP. The results showed that ip administration of TMP countered the effects of ig administration of MSG on behavior and histopathology, suggesting that TMP was a neuroprotective agent. This study provides evidence that TMP possesses obviously neuroprotection against glutamate-induced neurotoxicity, and the neuroprotection effect may result from its inhibiting expression of NMDARs, consequently blocking-up $\mathrm{Ca}^{2+}$ influx through the receptor's associated ion channel, which can be neurotoxic.
\end{abstract}

Keywords: Excitatory Amino Acids; Neurotoxicity; Neuroprotection; Tetramethylpyrazine; NMDARs; Mice

\section{Introduction}

Exitotoxicity based on the release of excitatory amino acids (EAAs), mainly glutamate, is a process by which glutamate or other EAAs induce neuronal cell death in the central nervous system (CNS) [1-3], and has been implicated in a variety of both acute and chronic degenerative diseases, including focal and global ischemia, hypoxia or traumatic brain injury, Parkinson's disease, Alzheimer's disease, Huntington's chorea, spinocerebellar degenerations, amyotrophic lateral sclerosis [3-5].

Some medicinal plants and traditional Chinese medicines and herbs or their extracts have showed effectiveness as neuroprotective agents [6-8]. Ligusticum chuanxiong Hort has the action of activating blood, regulating qi and expels wind [9]. Chuanxiongzine, 2,3,5,6-tetramethylpyrazine (TMP) (Figure 1), was isolated from several traditional Chinese medicines, such as Ligusticum Chuanxiong Hort, Curcuma aromatica Salisb, and Jatropya podagrica Hook [10]. TMP is colorless needle crystal, and is soluble in hot water. TMP can inhibit L-type calcium-channel current and release of intracellular calcium store in hippocampalneuronal cells, and exerts nerve protective effect [11]. Chinese scientists have contributed a

\footnotetext{
"Corresponding author.
}

lot to its investigation, and as an available blood-activating and stasis-eliminating component, it has been extensively applied to the treatment of vascular diseases of heart and brain, and obtained excellent efficiency in China [12]. Our previous experimental results revealed that that TMP possesses potent antidepressant-like activity $[8,13]$. The present study was to investigate the possible protective effect of TMP on glutamate-induced neurotoxicity in mice.

\section{Materials and Methods}

\subsection{Chemical and Drug}

MSG was purchased from Shanghai Bio Life Science \& Technology Co., Ltd. (China). TMP was purchased from National Institute for the Control of Pharmaceutical and Biological Products (Beijing, China). Rabbit anti-rat NMDAR1 polyclonal antibody was purchased from Up-<smiles>Cc1ncc(C)c(C)n1</smiles>

Figure 1. Chemical structure of chuanxiongzine. 
state Biotech (Lake, Placid, NY, USA). Histostain ${ }^{\mathrm{TM}}$ Plus Immunohistochemical reagent was purchased from Zymed Laboratories (South San Francisco, CA, USA), and a diaminobenzidine stain kit and ZLI-9001 APES were purchased from Zhongshan Biotech Ltd (Beijing, China).

\subsection{Instruments}

MG-3-type Y-maze stimulator purchased from Biomedical Instrument Factory of Zhangjiagang (Jiangsu Province, China).

\subsection{Animals}

Kunming (KM) mice, 7 weeks old, from the experimental animal center of Guangdong Medical College (Zhanjiang, China), were used in this study. Mice were provided with standard mouse food and chlorinated water ad libitum and kept at room temperature of $22^{\circ} \mathrm{C} \pm 1{ }^{\circ} \mathrm{C}$. They were kept on a reversed 12:12 h light-dark cycle. All animals were treated in compliance with the Guidance Suggestions for the Care and Use of Laboratory Animals issued by the Ministry of Science and Technology of China [14].

\subsection{Experimental Procedures}

The mice, except controls, were given MSG $(4.0 \mathrm{~g} / \mathrm{kg} / \mathrm{d}$, ig) or/and TMP $(10,20,40 \mathrm{mg} / \mathrm{kg} / \mathrm{d}$, ip) simultaneously for 10 days, and then their behaviors, histopathology and immunohistochemistry were studied $[15,16]$.

\subsection{Test of Y-Maze Discrimination Learning}

Test of Y-maze discrimination learning was carried out by Xu's method [17]. Test of Y-maze discrimination learning for 6 consecutive days started on day 1, and was repeated once on day 35 after the last treatment of MSG or/and TMP in mice. The results were recorded as the number of correct responses (Mean \pm SEM) from 20 trials.

\subsection{Test of Crawling along a Rope}

Test of crawling along a rope measures the animal's cooperation movement ability in high altitude stress. On day 10 after the last treatment with or without MSG or/and TMP the mice were placed on a 2-m-long rope, the distance of which was about $1.5 \mathrm{~m}$ from the ground, and then the behaviors of the mice were observed for 3 min. The mice which could grasp and crawl along the rope were deemed to have "succeeded" in the test, and those mice that could either not grasp a rope tightly or grasped the rope tightly but could not crawl along "failed" in the test.

\subsection{Examination of Histopathology}

36 days after the last treatment with or without MSG or/and TMP the mice were anaesthetized ip with sodium pentobarbital $(60 \mathrm{mg} / \mathrm{kg})$ and then sacrificed by perfusion fixation of the CNS with $10 \%$ formalin. The whole brain was excised carefully, and was further fixed in $10 \%$ formalin for a week. The hippocampus region of each animal was sectioned, and 10-mm-thick sections were cut and stained with hematoxylin and eosin. The sections cutting across hippocampus region were examined by light microscopy.

\subsection{Immunohistochemistry}

The whole brains of 4 unselected mice were excised carefully on day 36 after the last treatment of MSG or/and TMP. The brains were immediately fixed in $10 \%$ formalin in $0.1 \mathrm{M}$ phosphate buffer $(\mathrm{pH} 7.4)$ at $4^{\circ} \mathrm{C}$ for 2 days, and processed by paraffin embedding methods. Sections $4 \mu \mathrm{m}$ thick were cut and processed for inmunohistochemistry. The immunohistochemistry of NMDAR1 on sections was performed using a streptavidin-peroxidase conjugate (SP) method according to the manufacturers' instructions [18,19]. Primary antibody (see Chemicals) was diluted 1:100. After incubation of primary antibody at room temperature overnight, the sections were incubated with second antibody 15 min at room temperature, and the reaction was visualized with DAB. With negative controls, phosphate buffer solution (PBS) was used instead of primary antibody.

Sections obtained from all of the animals were matched for comparable hippocampal level. Brain regions were identified via a light microscope. NMDAR1 labels were identified by the characteristic yellowish brown stain seen in NMDAR1 positive cell bodies. Changes in the number of immunopositive cells of the hippocampal CA3 sector in stained sections were counted under a light microscope at a magnification of a $\times 100$ without the examiner knowing the experimental protocols, and the average of five different areas was determined.

\subsection{Statistical Analyses}

All data were statistically processed using SPSS 10.0 software (SPSS, Chicago, IL, USA) and were expressed as Mean \pm SEM. The repeated-measures analysis with a compound symmetry variance-covariance structure model was used to analyze the data from the Y-maze discrimination learning. The chi-square test was used to analyze the data from the crawling rope test. A P value less than 0.05 was considered statistically significant.

\section{Results}

\subsection{Protective Effect of TMP on MSG-Induced Lesion of Y-Maze Discrimination Learning and Memory}

As shown in Figure 2, ig administration of MSG (4.0 


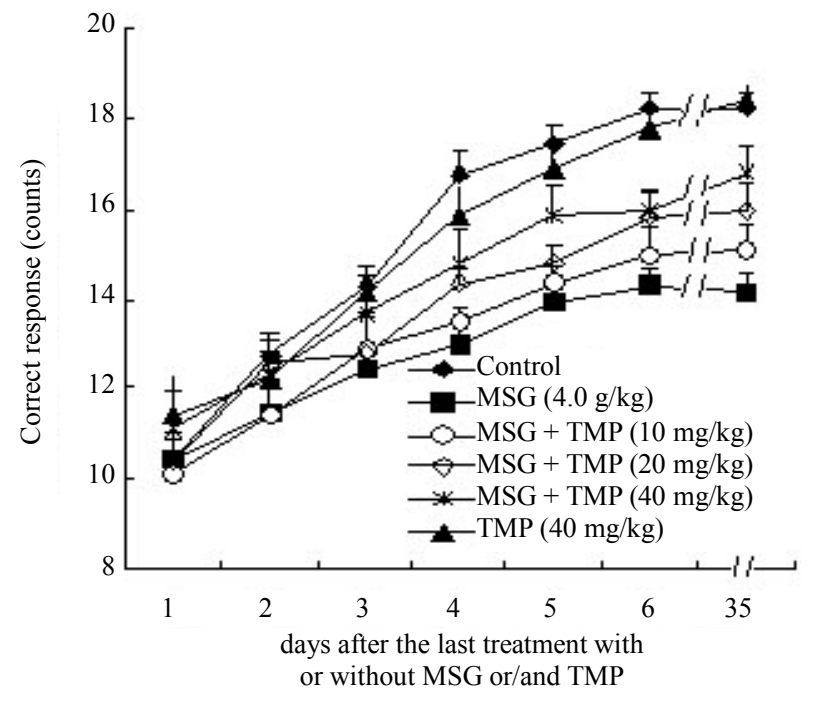

Figure 2. Protective effect of TMP on monosodium glutamate (MSG)-induced lesions of Y-maze discrimination learning and memory. Ten animals were used in each group. Vertical error bars represent the standard error of the mean. The repeated-measures analysis with an unstructured variance covariance structure model was used to analyze the data from $\mathrm{Y}$-maze discrimination learning test. $Y$-maze discrimination learning tests: comparison of $P$ values as follows.

\begin{tabular}{lc}
\hline \multicolumn{2}{c}{ Comparisons of P values } \\
\hline Comparisons & P values \\
TMP $40 \mathrm{mg} / \mathrm{kg}$ vs. Control & 0.75 \\
MSG $4.0 \mathrm{~g} / \mathrm{kg}$ vs. Control & $<0.01^{*}$ \\
MSG $4.0 \mathrm{~g} / \mathrm{kg}+$ TMP $20 \mathrm{mg} / \mathrm{kg}$ vs. Control & 0.36 \\
MSG $4.0 \mathrm{~g} / \mathrm{kg}+$ TMP $20 \mathrm{mg} / \mathrm{kg}$ vs. TMP $20 \mathrm{mg} / \mathrm{kg}$ & 0.25 \\
MSG $4.0 \mathrm{~g} / \mathrm{kg}+$ TMP $20 \mathrm{mg} / \mathrm{kg}$ vs. MSG $4.0 \mathrm{~g} / \mathrm{kg}$ & $<0.01^{*}$ \\
MSG $4.0 \mathrm{~g} / \mathrm{kg}+$ TMP $10 \mathrm{mg} / \mathrm{kg}$ vs. MSG $4.0 \mathrm{~g} / \mathrm{kg}$ & $>0.05$ \\
MSG $4.0 \mathrm{~g} / \mathrm{kg}+$ TMP $40 \mathrm{mg} / \mathrm{kg}$ vs. MSG $4.0 \mathrm{~g} / \mathrm{kg}$ & $<0.01^{*}$ \\
\hline
\end{tabular}

Superscript " " " indicates significant result at $\alpha=0.05$. TMP: tetramethylpyrazine; MSG: monosodium glutamate.

$\mathrm{g} / \mathrm{kg} / \mathrm{d} \times 10$ ) had deleterious effects on $\mathrm{Y}$-maze discrimination learning and memory in mice. The Y-maze discrimination learning and memory of mice treated with MSG were significantly less than those of control from the 1st to 6th, and 35th days after MSG treatment $(\mathrm{P}<$ 0.001). However, the Y-maze discrimination learning and memory of mice treated with TMP $(40 \mathrm{mg} / \mathrm{kg} / \mathrm{d} \times 10)$ or MSG $(4.0 \mathrm{~g} / \mathrm{kg} / \mathrm{d} \times 10)+\mathrm{TMP}(40 \mathrm{mg} / \mathrm{kg} / \mathrm{d} \times 10)$ and those of control seemed comparable $(\mathrm{P}>0.05)$. The results indicated that TMP had no obvious effects on the Y-maze discrimination learning and memory in the adult mice, apart from countering the deleterious effects of MSG on them.

\subsection{Protective Effect of TMP on MSG-Induced Disturbance of Cooperation Movement Ability under High-Altitude Stress}

As shown in Table $\mathbf{1}$ and Figure 3, a greater part of the mice treated with MSG could either not grasp a rope tightly or grasped the rope tightly but could not crawl along it, and cooperation movement ability under highaltitude stress of mice treated with $4.0 \mathrm{~g} / \mathrm{kg}$ of MSG was significantly less than that of control $(\mathrm{P}<0.01)$ and the mice treated with MSG $4.0 \mathrm{~g} / \mathrm{kg}+$ TMP $(20,40 \mathrm{mg} / \mathrm{kg})$. However, cooperation movement ability under high-altitude stress of the mice treated with TMP $40 \mathrm{mg} / \mathrm{kg}$ alone or MSG $4.0 \mathrm{~g} / \mathrm{kg}+$ TMP $40 \mathrm{mg} / \mathrm{kg}$ and that of control seemed comparable $(\mathrm{P}>0.05)$. Consequently, the results suggest that ip administration of TMP has no obvious effects on the cooperation movement ability of the mice under high-altitude stress, apart from countering the effects of MSG on it.

\subsection{Protective Effect of SF on MSG-Induced Histological Lesions}

It is well known that the area most sensitive to brain damage is the hippocampus, which plays an important role in learning and memory. The results showed MSGinduced lesions of hippocampus characterized by intracellular edema, neuronal degeneration and necrosis, and hyperplasia occurred in the mice (Figure 4(B)). However, no

Table 1. Comparison of cooperation movement ability under high-altitude stress.

\begin{tabular}{lccc}
\hline Group & $\begin{array}{c}\text { Mice } \\
(\mathrm{n})\end{array}$ & $\begin{array}{c}\text { Mice crawling } \\
\text { along rope (n) }\end{array}$ & $\mathrm{P}$ \\
\hline Control & 11 & 11 & \\
TMP $40 \mathrm{mg} / \mathrm{kg}$ & 12 & 11 & 0.92 \\
MSG $4.0 \mathrm{~g} / \mathrm{kg}$ & 12 & 5 & $<0.01^{\mathrm{a}}$ \\
MSG $4.0 \mathrm{~g} / \mathrm{kg}+$ TMP $10 \mathrm{mg} / \mathrm{kg}$ & 12 & 5 & 0.08 \\
MSG $4.0 \mathrm{~g} / \mathrm{kg}+$ TMP $20 \mathrm{mg} / \mathrm{kg}$ & 11 & 7 & $<0.05^{\mathrm{b}}$ \\
MSG $4.0 \mathrm{~g} / \mathrm{kg}+$ TMP $40 \mathrm{mg} / \mathrm{kg}$ & 12 & 9 & $<0.05^{\mathrm{b}}$ \\
\hline
\end{tabular}

${ }^{\mathrm{a}} \mathrm{P}<0.01,{ }^{\mathrm{b}} \mathrm{P}<0.05$, vs. control group.
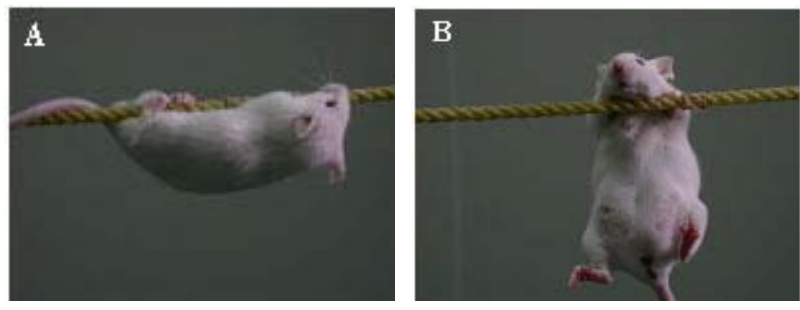

Figure 3. Comparison of cooperation movement ability under high-altitude stress. A: Mice crawling along rope; B: Mice could not crawling along rope. 
significant neuronal damage was detected in the hippocampuses of the mice treated with TMP or MSG + TMP (Figures 4(C)-(F)).

\subsection{Protection of TMP against MSG-Induced Expression of NMDAR1}

Evidence of NMDAR1 basal expression in controls was barely detectable. NMDAR1 expression in hippocampi was obviously up-regulated in the mice treated with MSG (Figures 5(A)((a) and (b))). In contrast, TMP reversed the effcet of MSG on the expression of NMDAR1 in the mice treated with MSG + TMP in a dose-dependent manner (Figures 5(A)((c)-(e)) and (B)).

\section{Discussion}

Exitotoxicity based on the release of Excitatory amino acid (EAAs), mainly Glu, is a process by which Glu or other EAAs induce neuronal cell death in the CNS $[1,20,21]$, and has been implicated in a variety of both acute and chronic degenerative diseases, including focal and global ischemia, hypoxia or traumatic brain injury, Parkinson's disease, Alzheimer's disease, Huntington's chorea, spinocerebellar degenerations, amyotrophic lateral sclerosis [22-24]. In our previous investigation demonstrated that MSG can produce excitotoxicity and in-
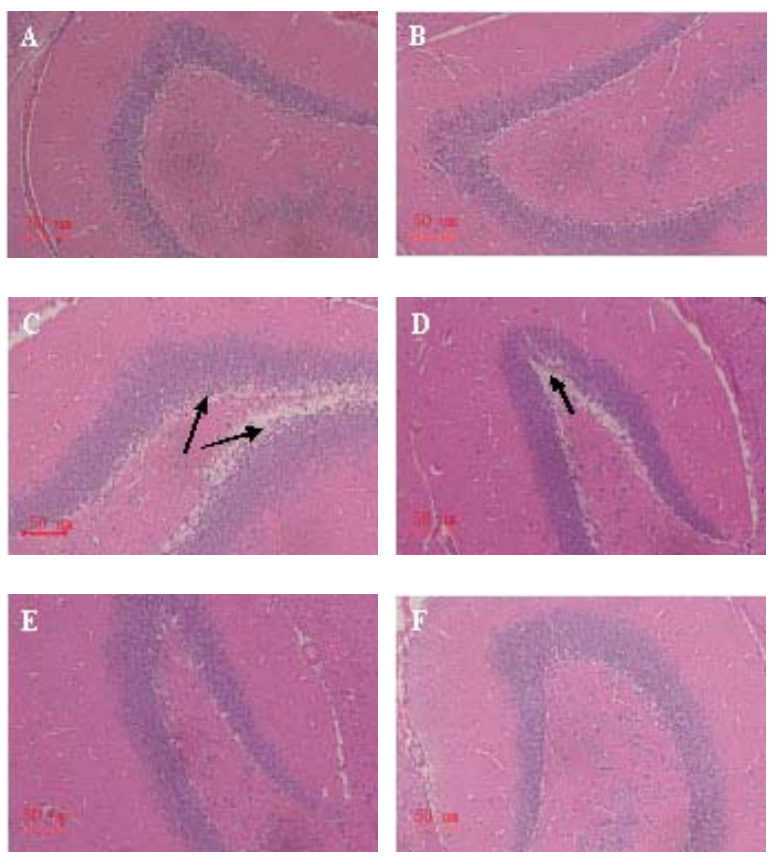

Figure 4. Sections through hippocampal regions of mice treated with MSG and/or TMP at late stages of pregnancy. A: Control; B: TMP $40 \mathrm{mg} / \mathrm{kg}$; C: MSG $4.0 \mathrm{~g} / \mathrm{kg}$; D: MSG $4.0 \mathrm{~g} / \mathrm{kg}+$ TMP $10 \mathrm{mg} / \mathrm{kg}$; E: MSG $4.0 \mathrm{~g} / \mathrm{kg}+$ TMP 20 $\mathrm{mg} / \mathrm{kg}$; F: MSG $4.0 \mathrm{~g} / \mathrm{kg}+$ TMP $40 \mathrm{mg} / \mathrm{kg}$. Arrow indicates neuronal degeneration, necrosis and hyperplasia. Scale bar, $50 \mu \mathrm{m}$.

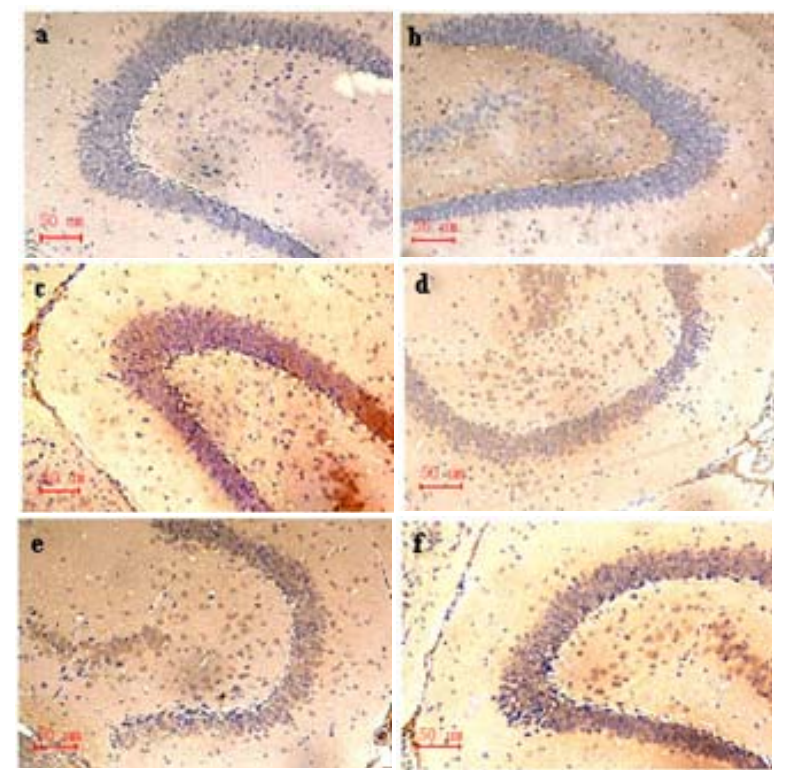

(A)

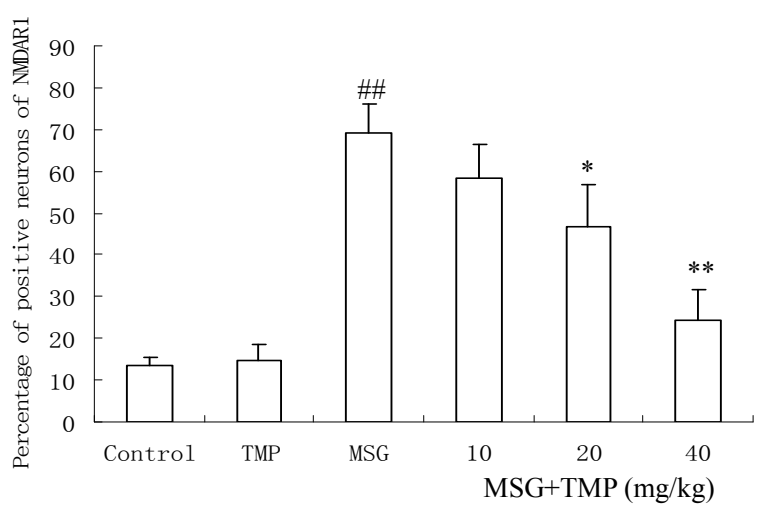

(B)

Figure 5. N-methyl-D-aspartate receptor type 1 (NMDAR1) receptor expression in the mouse hippocampus. The whole brains of unselected mice $(n=4)$ were immediately fixed in $10 \%$ formalin, and processed by paraffin embedding methods. Sections $4 \mu \mathrm{m}$ thick were cut and processed for inmunohistochemistry. The immunohistochemistry of NMDAR1 on sections was performed using a streptavidin- peroxidase conjugate (SP) method according to the manufacturer's instructions. Rabbit anti-rat polyclonal antibody (anti-NMDAR1) labels were identified by the characteristic yellowish brown stain seen in NMDAR1 positive cell bodies. Changes in the number of immunopositive cells of the hippocampal CA3 sector in stained sections were counted under a light microscope at a magnification of $a \times 100$ without the examiner knowing the experimental protocols, and the average of five different areas was determined. All values were expressed as the means \pm SEM, and statistical significance was evaluated by Dunnet's multiple comparison test for nonparametric analysis. A: NMDAR1 expression in the mouse hippocampus: a: Control; b: TMP $40 \mathrm{mg} / \mathrm{kg}$; c: MSG $4.0 \mathrm{~g} / \mathrm{kg}$; d: MSG $4.0 \mathrm{~g} / \mathrm{kg}+$ TMP $10 \mathrm{mg} / \mathrm{kg}$; e: MSG $4.0 \mathrm{~g} / \mathrm{kg}+$ TMP $20 \mathrm{mg} / \mathrm{kg}$; f: MSG $4.0 \mathrm{~g} / \mathrm{kg}+$ TMP $40 \mathrm{mg} / \mathrm{kg}$. Scale bar, $50 \mu \mathrm{m}$; B: Percentage of positive neurons of NMDAR1. 
duce brain damage $[7,15,25]$. In the present study, our results show that ig administration of excessive MSG makes significantly a series of behavioral disorders, including hyperactivity, lesions of learning and memory, and disturbance of cooperation movement ability under high-altitude stress, neuronal degeneration and necrosis, up-regulation of NMDAR1 expression in the brains of the mice treated with MSG, and simultaneous administration of TMP reverses the effects of MSG on behaviors, histopathology and NMDAR1 expression.

Glu elicits neurotoxic effects via distinct receptor and non-receptor-mediated mechanisms. GluRs are composed of two distinct classes, ionotropic and metabotropic receptors. The ionotropic GluRs (iGluRs) are ligand-gated cation channels consisting of several different subclasses including NMDA, $\alpha$-amino-3-hydroxy-5-methyl-4-isopxazole propionic acid (AMPA), kainate and $\delta$. The NMDA receptor (NMDAR) is composed of hetero-oligomers of NR1, NR2A-NR2D, and NR3A subunits (also called $\mathrm{x}-1$ or NMDAR-like subunits). NR1 is a key subunit that confers essential functions of the NMDAR and is expressed ubiquitously in the central nervous system. NMDAR activity mediates the expression of neuropeptides. Excessive stimulation of the three types of iGluRs, including NMDA, AMPA and kainate receptors, results in neuronal cell death by increasing $\mathrm{Ca}^{2+}$ and $\mathrm{Na}^{+}$influx and therefore dramatically changing the normal cellular physiology [21]. The NMDAR1 subunit is an essential part of NMDARs. Therefore, an increase in its expression may reflect an overall increase in levels of NMDARs in the hippocampi. Activation of NMDARs results in a $300 \%-400 \%$ increase in $\mathrm{Ca}^{2+}$ influx, which can be neurotoxic [26].

Further, excitotoxic cell death is due, at least in part, to excessive activation of NMDA-type iGluRs and hence excessive $\mathrm{Ca}^{2+}$ influx through the receptor's associated ion channel. Glu acts in about $30 \%$ of synapses in the central nervous system. It is kept in specific vesicles and is released in small doses that binds to receptors and is then metabolized by specific enzymes [27]. Glutamate opens the receptor dependent channel and then a large quantity of calcium enters the cells, which is highly toxic. Under normal conditions, $\mathrm{Ca}^{2+}$ levels are stable and low, around 10,000 times lower than the extracellular level. This leads to an increase of cerebral edema and excess $\mathrm{Ca}^{2+}$ stimulates a sequence of toxic enzymatic reactions leading to cell death [28]. The transient overflow of $\mathrm{Ca}^{2+}$, which follows the abnormal stimulation of GluRs, activates a number of intracellular mechanisms that are potential sources of reactive oxygen species (ROS) [24,29]. In turn, production of ROS gives rise to a series of intracellular events such as lipid peroxidation, protein oxidation and protein cross-linking that result in cell death [30]. The abnormal ROS production that follows ischemia/ reperfusion is by itself a cause of excessive release of Glu into the synaptic cleft that in turn triggers the excitotoxic process. Following these observations, it has been proposed that both excitotoxicity and oxidative stress cooperates in a vicious cycle to the early onset and subsequent propagation of neuronal injury [31]. These two events strictly interconnected eventually result in neuronal death in both acute and degenerative diseases. Physiological NMDAR activity, however, is also essential for normal neuronal function; potential neuroprotective agents that block virtually all NMDAR activity will very likely have unacceptable clinical side effects. Furthermore, excitotoxicity is a particularly attractive target for neuroprotective efforts because it is implicated in the pathophysiology of a wide variety of acute and [32]. The challenge chronic neurodegenerative disorders facing those trying to devise strategies for combating excitotoxicity is that the same processes, in excess, that lead to excitotoxic cell death are, at lower levels, absolutely critical for normal neuronal function. Until recently, drugs that showed the most promise as inhibitors of excitotoxicity also blocked normal neuronal function and conesquently had severe and unacceptable side effects. For this reason, many NMDAR antagonists have failed advanced clinical trials for a number of diseases including stroke and neurodegenerative disorders [33].

To sum up, the present study indicates that TMP appears to be safe and exhibits neuroprotection against excitotoxicity. It also reverses MSG-induced behaviora and histopathological lesions, and the effects of MSG on NMDAR1 expression. This suggests that TMP may be beneficial as a neuroprotective agent in the prevention and treatment of neurodegenerative and elated excitotoxic disorders.

\section{Acknowledgements}

The authors would like to thank Dr. Depu Yu for his great encouragement and continuous promotion.

\section{REFERENCES}

[1] J. W. Olney, O. L. Ho and V. Rhee, "Cytotoxic Effects of Acidic and Sulphur Containing Amino Acids on the Infant Mouse Central Nervous System," Experimental Brain Research, Vol. 14, No. 1, 1971, pp. 61-76. doi:10.1007/BF00234911

[2] M. Jiang, H. Sun and Y. Q. Zhang. "Excitotoxic Effect of Glutamate on the Afferent Neurons in Guinea Pig," Journal of Central South University (Medical Sciences), Vol. 29, No. 2, 2004, pp. 170-173.

[3] H. Y. Zhang, Z. R. He, J. Yi, J. Gu, W. C. Liu, et al, "Morphological Study on Excitotoxic Neurodegeneration of Exogenous Glutamate in New Born Rat Brain," Chinese Journal of Anatomy, Vol. 25, No. 4, 2002, pp. 345349. 
[4] L. Alberghina and A. M. Colangelo, "The Modular Systems Biology Approach to Investigate the Control of Apoptosis in Alzheimer's Disease Neurodegeneration," BMC Neuroscience, Vol. 7, No. 1, 2006, pp. 27-32. doi:10.1186/1471-2202-7-27

[5] Y. Nishizawa, "Glutamate Release and Neuronal Damage in Ischemia," Life Science, Vol. 69, No. 4, 2001, pp. 369381. doi:10.1016/S0024-3205(01)01142-0

[6] Q. Mao, Z. Huang, S. Ip and C. Che, "AntidepressantLike Effect of Ethanol Extract from Paeonia Lactiflora in Mice," Phytotherapy Research, Vol. 22, No. 11, 2008, pp. 1496-1499. doi:10.1002/ptr.2519

[7] Y. P. Zhang, L. J. Yu, R. D. Ma, L. Bao, R. Zeng, et al., "Potent Protective Effects of Ferulic Acid on GlutamateInduced Neurotoxicity in Adult Mice," Chinese Journal of Neuromedicine, Vol. 7, No. 6, 2008, pp. 596-606.

[8] L. J. Yu, X. D. Jiang, Y. P. Zhang, M. N. Liao, R. D. Ma, et al., "Antidepressant-Like Activity of Tetramethylpyrazine Measured by Chronic Experimental Method in Rat Model of Depression," Pharmacology \& Pharmacy, Vol. 3, No. 1, 2012, pp. 52-57. doi:10.4236/pp.2012.31008

[9] G. Liu, "Chinese Herbal Mdicine," Hua Xia Publishing House, Beijing, 2001, pp. 227-228.

[10] H. B. Li and F. Chen, "Preparative Isolation and Purification of Chuanxiongzine from the Medicinal Plant Ligusticum Chuanxiong by High-Speed Counter-Current Chromatography," Journal of Chromatography A, Vol. 1047, No. 2, 2004, pp. 249-253.

[11] M. Su, Y. Zhou and G. Yang, "Effects of Tetramethylpyrazine on L-Type Calcium-Channel Current and the Intracellular Calcium Concentration in Primary Cultured Hippocampal Neuronal Cells," Chinese Journal of Rehabilitation, Vol. 23, No. 1, 2008, pp. 17-19.

[12] Y. B. Ji, "Pharmacological Action and Application of Blood-Activating and Stasis-Eliminating Available Composition of Traditional Chinese Medicine," Heilongjiang Science and Technique Press, Harbin, 1999, pp. 118-121.

[13] L. Yu, X. Jiang, M. Liao, R. Ma and T. Yu, "Antidepressant-Like Effect of Tetramethylpyrazine in Mice and Rats," Neuroscience \& Medicine, Vol. 2, No. 6, 2011, pp. 142148. doi: $10.4236 / \mathrm{nm} .2011 .22020$

[14] The Ministry of Science and Technology of the People's Republic of China, "Guidance Suggestions for the Care and Use of Laboratory Animals," 2006.

[15] T. X. Yu, Y. Zhao, W. C. Shi, R. D. Ma and L. J. Yu, "Effects of Maternal Oral Administration of Monosodium Glutamate at a Late Stage of Pregnancy on Developing Mouse Fetal Brain," Brain Research, Vol. 747, No. 2, 1997, pp. 195-206. doi:10.1016/S0006-8993(96)01181-X

[16] J. Podhorna and R. E. Brown, "Strain Differences in Activity and Emotionality Do Not Account for Differences in Learning and Memory Performance between C57BL/6 and DBA/2 Mice," Genes Brain and Behavior, Vol. 1, No. 2, 2002, pp. 96-110.

[17] B. H. Xu, H. F. Duan and R. Y. Liu, "The Effect on Learing and Memory of Application of RNAase to Hippocampus of Rats," Chinese Science Bulletin, Vol. 24, No. 2, 1979, pp. 182-185.
[18] J. Q. Chen, W. H. Zhan, Y. L. He, J. S. Peng, J. P. Wang, et al., "Expression of Heparanase Gene, CD44v6, MMP-7 and $\mathrm{nm} 23$ Protein and Their Relationship with the Invasion and Metastasis of Gastric Carcinomas," World Journal of Gastroenteroenterology, Vol. 10, No. 6, 2004, pp. 776-782.

[19] Z. R. Shi, S. H. Itzkowitz and Y. S. Kim, “A Comparison of Three Immunoperoxidase Techniques for Antigen Detection in Colorectal Carcinoma Tissues," Journal of Histochemistry and Cytochemistry, Vol. 36, No. 3, 1988, pp. 317-322. doi: $10.1177 / 36.3 .3278057$

[20] D. W. Choi, "Methods for Antagonizing Glutamate Neurotoxicity," Cerebrovascular \& Brain Metabolism Reviews, Vol. 2, No. 2, 1990, pp. 105-147.

[21] D. W. Choi, "Excitotoxic Cell Death," Journal of Neurobiology, Vol. 23, No. 9, 1992, pp. 1261-1276. doi:10.1002/neu.480230915

[22] D. W. Choi, "Glutamate Neurotoxicity and Diseases of the Nervous System," Neuron, Vol. 1, No. 8, 1988, pp. 623-634. doi:10.1016/0896-6273(88)90162-6

[23] W. O. Whetsell Jr., "Current Concepts of Excitotoxicity," Journal of Neuropathology \& Experimental Neurology, Vol. 55, No. 1, 1996, pp. 1-13. doi:10.1097/00005072-199601000-00001

[24] R. Pellicciari, G. Costantino, M. Marinozz and B. Natalini, "Modulation of Glutamate Receptor Pathways in the Search for New Neuroprotective Agents," Farmaco, Vol. 53, No. 4, 1998, pp. 255-261. doi:10.1016/S0014-827X(98)00018-4

[25] L. Yu, Y. Zhang, R. Ma, L. Bao, J. Fang, et al., "Potent Protection of Ferulic Acid against Excitotoxic Effects of Maternal Intragastric Administration of Monosodium Glutamate at a Late Stage of Pregnancy on Developing Mouse Fetal Brain," European Neuropsychopharmacology, Vol. 16, No. 3, 2006, pp. 170-177. doi:10.1016/j.euroneuro.2005.08.006

[26] B. Cheng and M. P. Mattson, "IGF-I and IGF-II Protect Cultured Hippocampal and Septal Neurons against Calcium-Mediated Hypoglycemic Damage," Journal of Neuroscience, Vol. 12, No. 4, 1992, pp. 558-566.

[27] D. W. Choi and S. M. Rothan, "The Role of Gutamate Neurotoxicity in Hipoxic-Ischemic Neuronal Death," Annual Review of Neuroscience, Vol. 13, 1990, pp. 171-182. doi:10.1146/annurev.ne.13.030190.001131

[28] R. J. Gagliadi, "Neuroprotection, Excitotoxicity and NMDA Antagonists," Arquivos de Neuro-Psiquiatria, Vol. 58, No. 2B, 2000, pp. 583-588. doi:10.1590/S0004-282X2000000300030

[29] P. H. Chan, "Role of Oxidants in Ischemic Brain Damage," Stroke, Vol. 27, No. 6, 1996, pp. 1124-1128. doi:10.1161/01.STR.27.6.1124

[30] E. R. Stadtman and B. S. Berlett, "Reactive Oxygen-Mediated Protein Oxidation in Aging and Disease," Drug Metabolism Reviews, Vol. 30, No. 2, 1998, pp. 225-243. doi: 10.3109/03602539808996310

[31] D. E. Pellegrini-Giampietro, G. Cherici, M. Alesiani, et al., "Excitatory Amino Acid Release and Free Radical Formation May Cooperate in the Genesis of Ischemia- 
Induced Neuronal Damage," Journal of Neuroscience, Vol. 10, No. 3, 1990, pp. 1035-1041.

[32] S. A. Lipton and P. A. Rosenberg, "Mechanisms of Disease: Excitatory Amino Acids as a Final Common Pathway in Neurologic Disorders," The New England Journal of Medicine, Vol. 330, No. 9, 1994, pp. 613-622. doi:10.1056/NEJM199403033300907
[33] R. L. Sacco, J. T. DeRosa, E. C. Haley, et al., "Glycine Antagonist in Neuroprotection for Patients with Acute Stroke: GAIN Americas: A Randomized Controlled Trial," Journal of the American Medical Association, Vol. 285, No. 13, 2001, pp. 1719-1728.

doi:10.1001/jama.285.13.1719 